\title{
Factors affecting the persistence of some residual herbicides in maize silage fields
}

\author{
A. Rahman, T.K. James, M.R. Trolove and C. Dowsett \\ AgResearch, Ruakura Research Centre, Private Bag 3123, Hamilton 3240, New Zealand \\ Corresponding author: anis.rahman@agresearch.co.nz
}

\begin{abstract}
The persistence of residual herbicides used in maize (Zea mays) silage crops was investigated in three field trials located in Waikato, Taranaki and Canterbury. Herbicides used included atrazine and acetochlor applied pre-emergence and mesotrione and nicosulfuron applied 6-12 weeks after planting. Bioassay of soil samples collected about the time of silage harvest showed small but biologically toxic residues of only nicosulfuron and only at the Taranaki site. A subsequent glasshouse study investigated whether the differences in persistence of nicosulfuron were due principally to soil characteristics (four soil types) or rainfall (amount and timing). Heavy rainfall $(50 \mathrm{~mm})$ in the first week or two after application or for several consecutive weeks was more effective in leaching the herbicide and reducing the residues than light $(10 \mathrm{~mm})$ or moderate $(25 \mathrm{~mm})$ rain applied at similar times. Also, residues of nicosulfuron disappeared faster in soils with low $\mathrm{pH}$ and high organic matter.
\end{abstract}

Keywords persistence, residues, bioassay, maize silage, nicosulfuron, atrazine, acetochlor, mesotrione.

\section{INTRODUCTION}

In New Zealand maize (Zea mays) crops are now commonly grown for silage during summer, often followed by a complementary winter crop, such as annual ryegrass (Lolium multiflorum) and oats (Avena sativa), which is used for grazing or ensiled. Land area for this cropping system is increasing to meet the growing feed demands of the dairy industry. Thus it is important that the production of both summer and winter crops is optimised.

Maize crops are usually treated with a preemergence and/or a post-emergence herbicide (Rahman 1988) and past research has shown that sometimes these can persist in the soil at concentrations large enough to damage sensitive crops in the rotation (Rahman \& James 1994).
As silage crops are harvested earlier than grain crops, the chances for damage to sensitive species are even greater.

The persistence of soil-applied herbicides is known to vary considerably between different soil types as well as climatic regions. A large volume of published information is available in New Zealand showing that both the initial phytotoxicity and residual activity of herbicides used in maize crops are strongly influenced by soil characteristics and environmental factors, such as the amount and timing of rainfall and soil temperature (Rahman \& James 1994, 1995, 2002). For most herbicides, the soil organic matter content and soil texture are the major factors affecting their phytotoxicity and 
persistence in the soil (Hance 1984; Kookana et al. 1998; Rahman \& Matthews 1979; Rahman \& James 1995, 2002). However, the soil behaviour of certain herbicides, for example those belonging to triazine and sulfonylurea groups, is also influenced markedly by soil pH levels (Brown 1990; Kookana et al. 1998; Rahman et al. 1996; Sarmah et al. 1998).

The objectives of this study were (i) to assess the level of residual activity of common maize herbicides in commercial maize silage fields on typical soil types in different regions and (ii) to investigate the influence of soil characteristics and rainfall amount and timing on the disappearance of residues in different soils.

\section{MATERIALS AND METHODS}

\section{Establishment of standards and bioassay of samples in glasshouse}

As a first step, glasshouse experiments were conducted to establish bioassay calibration standard curves for known concentrations of each herbicide in untreated soil from each site. Details of this procedure have been described previously (Rahman 1989). Briefly, a range of herbicide concentrations (between 0.001 and $1.0 \mathrm{mg} / \mathrm{kg}$ by weight of dry soil) were individually made up in volumetric flasks and added to weighed amounts of untreated air-dry soil. The soil was thoroughly mixed by shaking it in a polythene bag, which was left overnight to equilibrate and then used for potting out the test plant species. Ten seeds of oats or 15 seeds of mustard (Sinapis alba) were planted at $2-3 \mathrm{~mm}$ depth in $500 \mathrm{ml}$ plastic pots, which were then placed in the glasshouse in a random layout with three replicates. All pots were sub-irrigated to maintain soil moisture between $80 \%$ and $100 \%$ field capacity. The plants were grown in the glasshouse for 4 weeks, assessed for visual damage regularly and then harvested to measure dry matter yield. The dose-response relationships were determined from these shoot dry weight data.

\section{Field trials and soil sampling}

Four field trials were conducted in commercial maize silage fields located in Northland, Waikato,
Taranaki and Canterbury. Unfortunately, the Northland trial was abandoned after a flash flood deposited a layer of silt over much of the site in early February. The soil type in Waikato was a Horotiu sandy loam ( $\mathrm{pH}$ 6.5, organic C 5.5\%), in Taranaki, an Egmont sandy loam ( $\mathrm{pH}$ 6.1, organic C 8.4\%) and in Canterbury, a Waimakariri silt loam ( $\mathrm{pH} 5.9$, organic C 3.7\%). All trials were arranged in a randomised block design with four replicates. Individual plots were $3 \mathrm{~m} \times 5 \mathrm{~m}$ with four rows of maize. Herbicide treatments included recommended label rates of two pre-emergence herbicides, acetochlor (Roustabout, $2.5 \mathrm{~kg}$ ai/ha) and atrazine (Gesaprim, $1.5 \mathrm{~kg}$ ai/ha), and two post-emergence herbicides, mesotrione (Callisto, $96 \mathrm{~g}$ ai/ha) and nicosulfuron (Latro, $60 \mathrm{~g}$ ai/ha). The untreated control plots were sprayed postemergence with the non-residual herbicide, bromoxynil (Emblem, $450 \mathrm{~g}$ ai/ha), to reduce unwanted weed growth. All herbicides were applied with a $\mathrm{CO}_{2}$ powered precision sprayer in 200 litres/ha water at $200 \mathrm{kPa}$ using TeeJet 11003 series nozzles.

Soil samples for determination of herbicide residues were collected about 1 month prior to harvest and at the harvest time of the silage crop. Soil cores were taken with a $7.5 \mathrm{~cm}$ diameter soil sampler to a depth of $10 \mathrm{~cm}$ to collect approximately $1.5 \mathrm{~kg}$ soil from each plot. At each sampling time the cores from each plot were bulked together before being brought to the glasshouse where they were thoroughly mixed and used for planting two pots of each bioassay species. Dates of planting and spraying of herbicides for each trial and the dates for soil samplings are provided in Table 1.

\section{Effect of rainfall and soil characteristics on persistence of nicosulfuron}

Because of the need to control the timing and amount of rainfall, this investigation was carried out under controlled conditions in the Plant Protection Glasshouses at Ruakura Research Centre, Hamilton. Soils for this experiment were collected from the top $10 \mathrm{~cm}$ of two sites from Waikato (Horotiu silt loam and a Kaipaki peaty loam) and one each from Hawke's Bay (Flaxmere 
Table 1 Dates of planting, spraying and soil sampling for the 3 trials.

\begin{tabular}{|c|c|c|c|c|c|}
\hline \multirow[b]{2}{*}{ Trial Site } & \multirow[b]{2}{*}{ Planting } & \multicolumn{2}{|c|}{ Spraying } & \multicolumn{2}{|c|}{ Soil sampling } \\
\hline & & Pre-em & Post-em & Pre-harvest & At harvest \\
\hline Waikato & 3.10 .08 & 9.10 .08 & 26.11 .08 & 3.02 .09 & 30.03 .09 \\
\hline Taranaki & 5.10 .08 & 13.10 .08 & 1.12 .08 & 18.02 .09 & 26.03 .09 \\
\hline Canterbury & 18.10 .08 & 22.10 .08 & 20.11 .08 & - & 20.03 .09 \\
\hline
\end{tabular}

sedimentary clay loam) and Taranaki (Egmont sandy loam). Some soil characteristics as analysed by NZ Labs in Hamilton are given in Table 2.

Field moist soils were passed through the soil shredder, to break up large clumps and aid planting. Plastic pots ( $15 \mathrm{~cm}$ diameter) were filled with the processed soil. The herbicide treatment of nicosulfuron ( $60 \mathrm{~g}$ ai/ha) was applied on 9 July 2010 to the bare soil with a moving belt precision sprayer fitted with a TeeJet $8001 \mathrm{E}$ nozzle and applying 200 litres at $200 \mathrm{kPa}$. After treatment the pots were laid out in a randomised block design on glasshouse benches. The pots were subjected to eight different rainfall events on a weekly basis for 6 consecutive weeks commencing 1 week after treatment. These were light rain weekly (average of $10 \mathrm{~mm}$, range $9.6-17.1 \mathrm{~mm}$ ); medium rain weekly (average of $25 \mathrm{~mm}$, range 16.2-33.7 mm); heavy rain weekly (average of $50 \mathrm{~mm}$, range 30.3$55.2 \mathrm{~mm}$ ); and weekly light rainfall plus a heavy rainfall event at 1, 2, 3 or 4 weeks after treatment. Each rainfall treatment included five herbicidetreated pots and one untreated pot of soil.

Simulated rainfall was applied with an oscillating sprinkler, with the heavy rainfall applied over $60 \mathrm{~min}$ and the light rainfall over 30 min. Amount of rainfall events were estimated from rainfall measurements collected from the Ruakura Research Centre weather station between 1997 and 2010. Heavy rainfall $(50 \mathrm{~mm})$ was calculated as the average of the maximum daily rainfall figures and light rainfall $(10 \mathrm{~mm})$ as the average of the minimum daily rainfall throughout the 13 years. Medium rainfall amount (25 mm) was set as a figure between these rates.

Each pot's surface was divided into quarters, and into each quarter 10 mustard seeds were planted at $6,9,12$ or 15 weeks after herbicide treatment. Plants were given a visual score for herbicide damage and reduction in foliage growth as a percentage of the untreated control after 4 weeks of growth. Plants were then harvested for dry matter determinations by cutting them to ground level and drying at $80^{\circ} \mathrm{C}$ for $48 \mathrm{~h}$. All data were subjected to ANOVA to separate the means. The treatment arithmetic means and least significant differences (LSD) are presented in Table 4.

\section{RESULTS AND DISCUSSION}

\section{Establishment of standards in the glasshouse}

Of the two bioassay species evaluated, mustard was more sensitive than oats to all herbicides evaluated. Herbicidal injury included morphological aberrations (kinking or twisting of the leaves, reduction in the number or

Table 2 Some characteristics for different soils used in various trials.

\begin{tabular}{lllrrrrrr}
\hline Site & $\mathrm{pH}$ & $\mathrm{P}^{1}$ & $\mathrm{~K}^{2}$ & $\mathrm{Ca}^{2}$ & $\mathrm{Mg}^{2}$ & $\mathrm{Na}^{2}$ & $\mathrm{~S}_{\left(\mathrm{SO}_{4}\right)^{3}}$ & Organic $\mathrm{C}^{4}$ \\
\hline Waikato silt loam & 7.2 & 41 & 12 & 19 & 17 & 5 & 28 & 5.6 \\
Hawke's Bay & 5.7 & 18 & 15 & 12 & 52 & 9 & 7 & 3.5 \\
Taranaki & 6.1 & 61 & 11 & 15 & 23 & 9 & 18 & 8.4 \\
Waikato peat & 5.6 & 57 & 13 & 9 & 26 & 6 & 23 & 12.3 \\
Canterbury & 5.9 & 25 & 9 & 13 & 33 & 12 & 11 & 3.7 \\
\hline
\end{tabular}

${ }^{1} \mu \mathrm{g} / \mathrm{ml},{ }^{2} \mathrm{MAF}$ QT; ${ }^{3} \mathrm{ppm} ;{ }^{4} \%$ 
serration of lobes), discolouration and yellowing of foliage, stunting and ultimate death of plants at higher concentrations. At low concentrations the visual damage was confined to the first one or two leaves and in such cases the seedlings recovered within 2 weeks and normal plant growth (and dry matter) was produced afterwards.

The level of phytotoxicity of all herbicides to the bioassay species varied between the soil types. The detection limits (rates that caused $15 \%$ or greater reduction in dry weights) for each herbicide as determined by bioassay calibration standards are presented in Table 3. These show that atrazine was considerably more phytotoxic in the Canterbury soil, which had the lowest $\mathrm{pH}$ and organic $C$ level of the three soils used for bioassays. Nicosulfuron was more active in the Waikato and Taranaki soils, which had higher $\mathrm{pH}$ and organic C. The activity of other herbicides was not correlated to the same extent to these soil characteristics.

As an example, the dose response curve for nicosulfuron in the Taranaki soil using mustard as the bioassay species is presented in Figure 1. This shows the significant increase in growth at very low concentrations (between 0.005 and 0.001 $\mathrm{mg}$ ai/kg soil) and marked reduction in growth commencing at about $0.0015 \mathrm{mg}$ ai/ $\mathrm{kg}$ soil. This is a typical phytotoxicity curve observed with many sulfonylurea herbicides (Rahman 1989).

\section{Persistence of herbicides in the field}

A brief summary of these results was provided by Trolove et al. (2009). Bioassay results of soil samples collected from field plots showed no phytotoxic residues from the two pre-emergence herbicides (atrazine and acetochlor) at any of

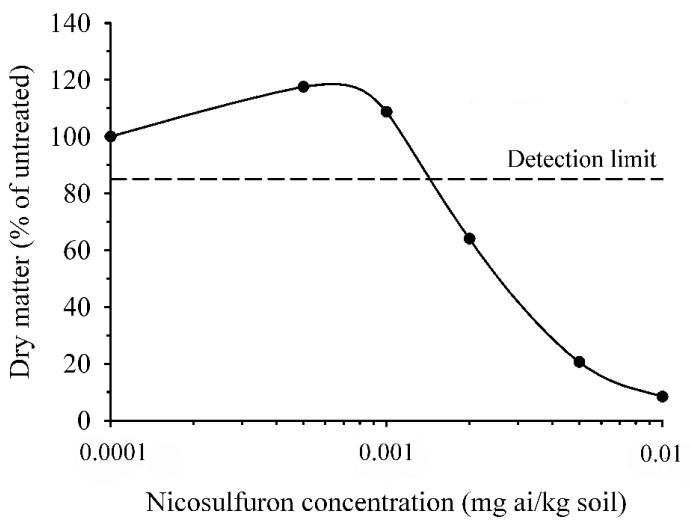

Figure 1 Mustard bioassay standard for nicosulfuron in the Taranaki soil. (Detection limit: $0.002 \mathrm{mg}$ ai/ $/ \mathrm{kg}$ soil.)

the trial sites at either sampling time. Similarly no phytotoxic residues of the post-emergence herbicide mesotrione were detected at any site. However, the mustard bioassay detected phytotoxic residues (about $0.005 \mathrm{mg}$ ai $/ \mathrm{kg}$ soil) of the post-emergence herbicide nicosulfuron at both sampling times at the Taranaki site.

\section{Effect of rainfall and soil characteristics on persistence of nicosulfuron}

The four soils evaluated here showed consistent results with respect to impact of rainfall on the dissipation of nicosulfuron. However, they differed considerably in the magnitude of the rainfall impact (Table 4). With the Waikato silt loam soil the bioassay at 6 weeks after treatment showed a high level of residual activity in all rainfall treatments except the weekly heavy rainfall where no residues were detected (Figure 2a). With this soil the residues persisted for

Table 3 Detection limits for herbicides as determined by mustard bioassay calibration standards.

\begin{tabular}{lccc}
\hline & \multicolumn{3}{c}{ Approximate detection limits (mg ai/kg soil) } \\
\cline { 2 - 4 } Herbicide & Waikato & Taranaki & Canterbury \\
\hline Atrazine & 0.5 & 0.1 & 0.01 \\
Acetochlor & 0.05 & 0.01 & 0.1 \\
Mesotrione & 0.02 & 0.005 & 0.02 \\
Nicosulfuron & 0.002 & 0.002 & 0.01 \\
\hline
\end{tabular}


the duration of the experiment in all the other rainfall treatments except in the pots that received a single heavy rainfall event 1 week after application where a reduction in residual herbicide activity occurred from weeks 9 to 15 .

At 6 weeks the Hawke's Bay soil also showed near complete dissipation of nicosulfuron in the weekly heavy rainfall treatment. Additionally, there was considerable loss of residual activity in the pots that received a single heavy rainfall event at either 2 or 3 weeks post-treatment (Table 4, Figure 2b). This was followed in week 9 with significant reductions in all rainfall treatments and by near complete absence of herbicide activity in all treatments at the 12 week assessment (Table 4).

Residual activity from nicosulfuron in the Taranaki soil at weeks 6 and 9 was very similar to that in the Waikato silt loam soil with near complete dissipation of detectable residues in the weekly heavy rainfall and commencing in week
9, partial dissipation in the single heavy rainfall at 1 week after treatment (Figure 2c). However, in this soil the remaining residues dissipated rapidly; first in the treatments receiving a single heavy rainfall at 1 to 4 weeks after application and finally in the light and medium weekly rainfall treatments (Table 4).

Results from the Waikato peat soil were variable (Table 4 ) but still showed a large and significant reduction in residual activity at 6 weeks in the weekly heavy rainfall treatment and a small reduction in activity in the single heavy rainfall at 1 week post application treatment. At 9 weeks there was considerable reduction in activity in all treatments but due to the large variation between pots in this soil, the only other treatment to have a significant reduction was the single heavy rainfall at 1 week after application. Few residues were detected during the 12 week bioassay. Growth of bioassay plants was very
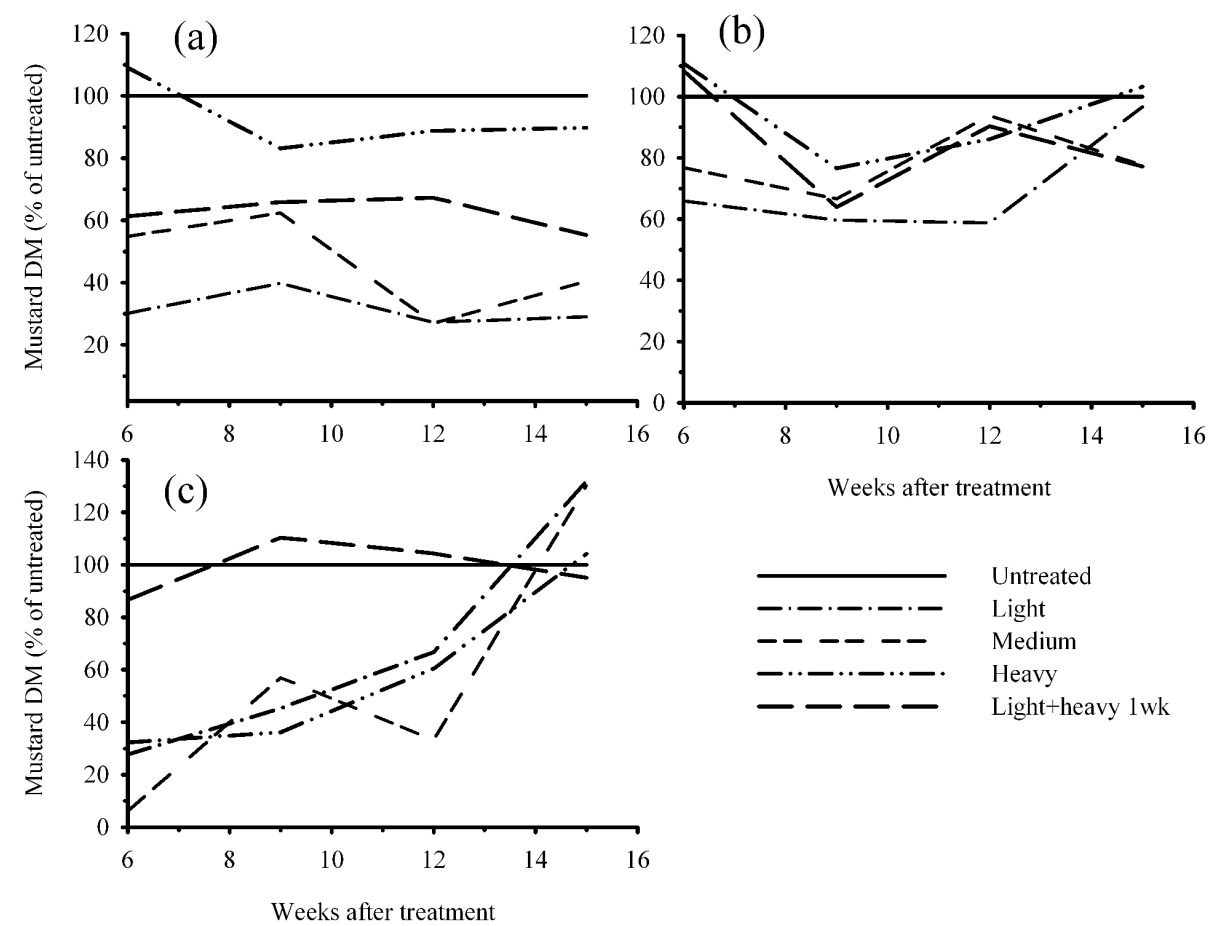

Figure 2 Mustard plant dry matter (\% of untreated) in glasshouse trials given various rainfall treatments plotted against time after nicosulfuron application. (a) Waikato silt loam soil, (b) Hawke's Bay soil and (c) Taranaki soil. Only selected treatments are shown. 
Table 4 Visual scores of damage and growth reduction caused by herbicide residues in different rainfall treatments at various times after herbicide application.

\begin{tabular}{|c|c|c|c|c|c|c|c|c|c|}
\hline \multirow{2}{*}{\multicolumn{2}{|c|}{$\begin{array}{l}\text { Weeks after } \\
\text { treatment Untreated }\end{array}$}} & \multirow[b]{2}{*}{ Light $^{1}$} & \multirow[b]{2}{*}{ Medium $^{2}$} & \multirow[b]{2}{*}{ Heavy $^{3}$} & \multicolumn{4}{|c|}{ Light $^{1}+$ Heavy $^{3}$ after $\mathrm{x}$ weeks } & \multirow{2}{*}{$\begin{array}{c}\text { LSD } \\
\mathrm{P} \leq 0.05\end{array}$} \\
\hline & & & & & 1 & 2 & 3 & 4 & \\
\hline \multicolumn{10}{|c|}{ Waikato - Horotiu silt loam } \\
\hline 6 & 0 & 95 & 95 & 0 & 93 & 95 & 95 & 97 & 1.3 \\
\hline 9 & 0 & 96 & 95 & 6 & 72 & 96 & 96 & 97 & 9.4 \\
\hline 12 & 0 & 95 & 91 & 0 & 24 & 93 & 93 & 95 & 8.8 \\
\hline 15 & 0 & 94 & 88 & 10 & 40 & 94 & 79 & 95 & 15.6 \\
\hline \multicolumn{10}{|c|}{ Hawke’s Bay - Flaxmere sedimentary clay loam } \\
\hline 6 & 0 & 95 & 95 & 18 & 85 & 79 & 67 & 96 & 18.1 \\
\hline 9 & 0 & 43 & 36 & 0 & 18 & 31 & 19 & 20 & 18.2 \\
\hline 12 & 0 & 4 & 0 & 0 & 0 & 0 & 16 & 12 & 7.3 \\
\hline 15 & 0 & 0 & 0 & 0 & 0 & 0 & 0 & 0 & - \\
\hline \multicolumn{10}{|c|}{ Taranaki - Egmont sandy loam } \\
\hline 6 & 0 & 96 & 96 & 8 & 93 & 96 & 95 & 96 & 3.9 \\
\hline 9 & 0 & 96 & 95 & 0 & 82 & 87 & 93 & 97 & 8.0 \\
\hline 12 & 0 & 87 & 87 & 0 & 20 & 0 & 8 & 10 & 17.1 \\
\hline 15 & 0 & 0 & 0 & 0 & 0 & 0 & 0 & 0 & - \\
\hline \multicolumn{10}{|c|}{ Waikato - Kaipaki peaty loam } \\
\hline 6 & 0 & 94 & 84 & 14 & 78 & 88 & 82 & 91 & 16.2 \\
\hline 9 & 0 & 59 & 79 & 17 & 0 & 45 & 51 & 58 & 52.2 \\
\hline 12 & 0 & 20 & 14 & 8 & 6 & 10 & 10 & 6 & 6.7 \\
\hline 15 & 0 & 56 & 58 & 0 & 0 & 0 & 48 & 53 & 33.2 \\
\hline
\end{tabular}

${ }^{1}$ Light $=10 \mathrm{~mm},{ }^{2}$ Medium $=25 \mathrm{~mm},{ }^{3}$ Heavy $=50 \mathrm{~mm}$.

patchy in the 15-week bioassay due to problems with wettability of this soil in the glasshouse environment and reduced growth was observed in some treatments not recorded at the 12 week assessment.

Data on dry matter of plants were quite variable as residues approached the detection limit. This is due to the well known response of sulfonylurea herbicides where plant growth is often promoted by very low concentrations of the herbicide (Rahman 1989). Nevertheless, the larger differences, namely the influence of heavy rainfall over consecutive weeks or heavy rainfall at the first week after treatment, were still quite obvious as shown by the examples presented in Figures $2 \mathrm{a}, \mathrm{b}$ and $\mathrm{c}$.

\section{General discussion}

Glasshouse bioassays of soil samples collected from the field showed that atrazine, acetochlor and mesotrione did not persist in phytotoxic amounts at silage harvest times at any of the trial sites. So it would appear that farmers may not need to worry about soil residues damaging the succeeding autumn/winter crops in the rotation when these herbicides are used in maize silage crops. This is a similar result to what has been found in most situations after a maize grain crop (Rahman \& James 1994, 2002). However, nicosulfuron applied post-emergence did exhibit some residual activity at silage harvest time in the soil from Taranaki, which was the last site treated post-emergence and with the least rainfall (180 mm cf. $215 \mathrm{~mm}$ Waikato and 350 mm Canterbury) between application and soil sampling (Trolove et al. 2009).

The glasshouse investigation was designed to look further into reasons why the residual activity of nicosulfuron lasted longer at the Taranaki site. Two questions were posed at the 
start of this investigation. The first related to the relative importance of soil characteristics versus rainfall events after herbicide application. It would appear that rainfall, especially in the first week or two after application would have the major influence on dissipation of nicosulfuron residues in all soils. This result would not be unexpected in view of the fact that nicosulfuron was found to be one of the sulfonylurea compounds that showed greater mobility in New Zealand soils than many other members of this group (Rahman \& James 1989). The second question related to the amount and timing of rainfall. The results show that light $(10 \mathrm{~mm})$ or medium $(25 \mathrm{~mm})$ amounts of rainfall during the season did not result in faster dissipation of nicosulfuron than what would be expected in most field situations. However, heavy rainfall $(50 \mathrm{~mm})$, especially during the first week or two after treatment accelerated dissipation of the herbicide from the treated soil with little or no phytotoxic residues detected at 6-9 weeks after herbicide application. As would be expected, heavy rainfall applied once a week over 6 weeks leached the herbicide even faster out of the treated soil.

Although rainfall was the major determinant in dissipation of nicosulfuron residues, there were significant differences between different soil types. Soil $\mathrm{pH}$ is known to be the major characteristic affecting the degradation rate of sulfonylurea herbicides. With enhanced chemical hydrolysis occurring at low $\mathrm{pH}$ levels, degradation is known to be faster in acidic soils (Beyer et al. 1988). Conversely the sulfonylureas have been shown to be quite persistent in more alkaline soils (Nicholls et al. 1987; Walker et al. 1989; Sarmah et al. 1998). In the present study the Waikato silt loam soil had the highest $\mathrm{pH}$ (Table 2), which would easily explain the long persistence of nicosulfuron in this soil. On the other hand, the residual activity disappeared fastest in the Hawke's Bay soil with a low $\mathrm{pH}$ level. The Waikato peat soil also had a similarly low $\mathrm{pH}$, but it had high organic matter, which would adsorb a considerable proportion of the applied herbicide (Guenther et al. 1989;
Walker et al. 1989). The greatest majority of soils in maize growing regions of New Zealand are known to be acidic ( $\mathrm{pH} 5.5-6.8)$ and have organic matter content greater than $5 \%$, with an average for volcanic soils in the vicinity of $10 \%$ to 12\% (Burney et al. 1975; Rahman \& James 2002). This should help in reducing the risk of long persistence of sulfonylurea herbicides in maize cropping in New Zealand.

In conclusion, it is unlikely that soil residues of most herbicides used in maize silage crops would adversely affect autumn/winter crop establishment in most soils in a normal growing season. Nicosulfuron was the only herbicide that persisted in phytotoxic amounts at the silage harvest time at one of the three sites. In glasshouse studies it persisted in the soil from 6 weeks to more than 15 weeks depending on the soil type and the amount and timing of rainfall after herbicide application. Heavy rainfall (50 $\mathrm{mm}$ ) in the first week or two after application or for several consecutive weeks was more effective in leaching the herbicide (or reducing the residues) than light $(10 \mathrm{~mm})$ or moderate $(25 \mathrm{~mm})$ rain applied at similar times. Also residues of nicosulfuron disappeared faster in soils with low $\mathrm{pH}$ and high organic matter levels.

\section{ACKNOWLEDGEMENTS}

Thanks are due to farmers who provided the trial sites in each region, Geoff Hurrell for assistance with the Canterbury site and Mike Parker for assistance at other trial sites and for collecting soils for glasshouse studies. Financial assistance for this project was provided by the Sustainable Farming Fund through the Foundation for Arable Research.

\section{REFERENCES}

Beyer EM Jr, Duffy MJ, Hay JV, Schluetter DD 1988. Sulfonylureas. In: Kearney PC, Kaufman DD ed. Herbicides: Chemistry, Degradation and Mode of Action Volume 3. Marcel Dekker, New York. Pp. 117-189.

Brown HM 1990. Mode of action, crop selectivity, and soil relations of the sulfonylurea herbicides. Pesticide Science 29: 263-281. 
Burney B, Rahman A, Oomen GAC, Whitham JM 1975. The organic matter status of some mineral soils in New Zealand. Proceedings of the $28^{\text {th }}$ New Zealand Weed and Pest Control Conference:101-103.

Guenther P, Rahman A, Pestemer W 1989. Quantitative bioassays for determining residues and availability to plants of sulfonylurea herbicides. Weed Research 29: 141-146.

Hance RJ 1984. Herbicide residues in soil: some aspects of their behaviour and agricultural significance. Australian Weeds 3: 26-34.

Kookana RS, Baskaran S, Naidu R 1998. Pesticide fate and behaviour in Australian soils in relation to contamination and management of soil and water: A review. Australian Journal of Soil Research 36: 715-764.

Nicholls PH, Evans AA, Walker A 1987. The behaviour of chlorsulfuron and metsulfuron in soils in relation to incidents of damage to sugar beet. Proceedings of the 1987 British Crop Protection Conference-Weeds: 549 $-556$.

Rahman A 1989. Sensitive bioassays for determining residues of sulfonylurea herbicides in soil and their availability to crop plants. In: Munawar M, Dixon G, Mayfield CI, Reynoldson T, Sadar MH ed. Environmental Bioassay Techniques and their Application. Kluwer Academic Publishers, Dordrecht. Hydrobiologia 188/189. Pp. 367-375.

Rahman A 1988. Recent major problems of weed control in maize in New Zealand. Proceedings of the International Congress of Crop Protection 53/3b. Pp. 1335-1342.

Rahman A, James TK 2002. Minimising environmental contamination by selecting appropriate herbicide dose. In: Kookana RS, Sadler R, Sethunathan N, Naidu R. ed. Environmental Protection and Risk Assessment of Organic Contaminants. Science Publishers Inc., Enfield, NH, USA. Pp. 209-224.
Rahman A, James TK 1995. Improving performance and reliability of soil applied herbicides in New Zealand. Proceedings of the $15^{\text {th }}$ Asian-Pacific Weed Science Society Conference: 627-635.

Rahman A, James TK 1994. Field persistence of some maize herbicides in two soils. Proceedings of the $47^{\text {th }}$ New Zealand Plant Protection Conference: 6-10.

Rahman A, James TK 1989. Comparative mobility of nine sulfonylurea herbicides in soil columns. Proceedings of the $12^{\text {th }}$ Asian-Pacific Weed Science Society Conference: 213-217.

Rahman A, James TK, Cornwell MJ 1996. Influence of lime on activity and persistence of tribenuron and thifensulfuron in soil. Proceedings of the $49^{\text {th }}$ New Zealand Plant Protection Conference: 202-206.

Rahman A, Matthews LJ 1979. Effect of soil organic matter on the phytotoxicity of thirteen $s$-triazine herbicides. Weed Science 27: 158-161.

Sarmah AK, Kookana RS, Alston AM 1998. Fate and behaviour of triasulfuron, metsulfuron methyl and chlorsulfuron in the Australian soil environment: a review. Australian Journal of Agricultural Research 49: 775-790.

Trolove MR, James TK, Rahman A., Hurrell G, Parker M 2009. Persistence of residual herbicides in maize silage fields. New Zealand Plant Protection 62: 417 (abstract only).

Walker A, CotterillEG, Welch SJ 1989. Adsorption and degradation of chlorsulfuron and metsulfuron methyl in soils from different depths. Weed Research 29: 281-287. 